\title{
Association of hypertension and obesity with HIV and antiretroviral therapy in a rural tertiary health center in Nigeria: a cross-sectional cohort study
}

\author{
This article was published in the following Dove Press journal: \\ Vascular Health and Risk Management \\ 18 March 2014 \\ Number of times this article has been viewed
}

\author{
Olarinde Jeffrey Ogunmola' \\ Olatunji Yusuf Oladosu' \\ Adeyemi Michael \\ Olamoyegun ${ }^{2}$ \\ 'Cardiac Care Centre, Department \\ of Internal Medicine, Federal Medical \\ Center, Ido Ekiti, Ekiti State, Nigeria; \\ ${ }^{2}$ Endocrinology, Diabetes and \\ Metabolism Unit, Department of \\ Internal Medicine, Ladoke-Akintola \\ University of Technology Teaching \\ Hospital, Ogbomoso, Oyo State, \\ Nigeria
}

Background: There are few studies from Nigeria and Africa regarding the contribution of obesity and hypertension to cardiovascular risk in HIV-infected patients. This study investigates the prevalence of hypertension and obesity and their association with HIV infection and antiretroviral treatment (ART).

Methods: We conducted a cross-sectional cohort study in a rural tertiary health center in Nigeria. The data collected included demographic variables, blood pressure, body mass index (BMI), monthly income, educational attainment, HIV status and ART treatment, duration of treatment, and CD4 T-lymphocyte count.

Results: A total of 403 participants met the inclusion criteria. There were $153(38.0 \%)$ HIV-negative subjects (42.5\% male, $57.5 \%$ female; mean age: $35.5 \pm 7.6$ years), $120(29.8 \%)$ HIV-positive drug-naïve subjects (42.5\% male, $57.5 \%$ female; mean age: $36.5 \pm 9.1$ years), and $130(32.2 \%)$ HIV-positive subjects taking antiretroviral drugs (33.1\% male, $66.9 \%$ female; mean age: $38.6 \pm 8.0$ years). The prevalence of hypertension was $13.7 \%$ in HIV-negative subjects, $19.0 \%$ in HIV-positive drug-naïve subjects, and $12.3 \%$ in HIV-positive ART subjects. The prevalence of obesity was $15.9 \%$ in the HIV-negative group, $3 \%$ in the HIV-positive drug-naïve group, and $8 \%$ in the HIV-positive ART group. Multivariate regression analysis showed no relationship between hypertension and HIV status $(P=0.293)$ or ART status $(P=0.587)$. In contrast, BMI showed a strong relationship with HIV status (odds ratio: $0.281 ; 95 \%$ confidence interval: $0.089-0.884 ; P=0.030)$ but not with ART status $(P=0.593)$. BMI was a significant predictor of hypertension.

Conclusion: HIV or ART status was not associated with hypertension. HIV infection was associated with a lower BMI, and a lower prevalence of obesity compared with HIV-negative subjects.

Keywords: cardiovascular risk, HIV infection, prevalence

\section{Introduction}

An estimated 33 million people worldwide are infected with human immunodeficiency virus (HIV). ${ }^{1}$ In the United States, approximately 1.1 million people have HIV infection, with 50,000 new infections each year. ${ }^{2}$ The impact of the HIV/acquired immunodeficiency syndrome (AIDS) epidemic has been greatest in sub-Saharan Africa, accounting for $67 \%$ (22.1 million) of the worldwide population infected with HIV, and the majority of global HIV-related deaths occur in this region. ${ }^{3}$ Nigeria has the second highest number living with HIV/AIDS in the world after South Africa, ${ }^{4}$ and an estimated 240,000 people in Nigeria died of AIDS in $2012 .^{3}$

An increasing prevalence of hypertension and obesity has been reported in lowto-middle income countries, including Nigeria..$^{5-9}$ In addition, there is some evidence
Correspondence: Olarinde Jeffrey Ogunmola

98 Oluwatuyi Quarters, opposite Rainbow Motel, PO Box 413, Akure,

Ondo State, Nigeria

Tel +2348033880875

Email joogunmola@yahoo.com 
to suggest that there is an excess risk of cardiovascular disease (CVD) among HIV-positive subjects with or without antiretroviral therapy (ART) compared with HIV-negative individuals. ${ }^{10-12}$ It has been suggested that, of the many factors that are involved in the development of CVD in HIV-positive patients, traditional cardiovascular risk factors are the main contributors. ${ }^{13}$

Today, Nigeria has the largest ART program in sub-Saharan Africa, ${ }^{14}$ with over 300,000 patients prescribed treatment in 2010; a massive increase in access to ART compared with 2002 when less than 10,000 patients were prescribed ART. HIV-infected patients who are adherent to highly active ART (HAART) have a longer life expectancy ${ }^{15}$ and, thus, are now developing diseases associated with older age. These include CVDs such as stroke and myocardial infarction. ${ }^{16-18}$ Concurrently, the epidemiology and demography of sub-Saharan Africa (including Nigeria) is shifting toward an older population with a higher prevalence of CVD resulting from chronic, non-communicable diseases. ${ }^{19-21}$ Studies have also implicated HIV infection and ART as potential mediators of this increased risk of CVD. ${ }^{17,18,22}$ These studies, however, have not included patients from sub-Saharan Africa. Furthermore, global efforts in Africa targeted at HIV care may need to utilize the same opportunity to improve overall cardiovascular health if chronic CVD risk factors are found to be highly prevalent. Studies in Nigeria have reported that hypertension is the most common cardiovascular risk factor for CVD. ${ }^{20,21,23,24}$ However, little is known about the relationship between hypertension or obesity, as cardiovascular risk factors, and HIV status with or without ART, in Africa and Nigeria in particular. Therefore, this research aimed to determine the prevalence of subjects with hypertension or obesity and to identify any association with HIV status and ART.

\section{Material and methods Study site and population}

This study was a cross-sectional cohort study conducted at the HIV clinic of the Federal Medical Centre, Ido Ekiti, Ekiti State, Southwest Nigeria. This tertiary health institution serves as referral center for other primary and secondary health institutions in the state and other neighboring states. However, large numbers of patients seek medical treatment in this center as a first point of contact. The HIV clinic receives patients referred as HIV-positive following screening tests with rapid kits. Participants in this study were enrolled into the following three groups:

- Group 1: HIV-negative apparently healthy individuals.

- Group 2: HIV-positive patients (ART-naïve).
- Group 3: HIV-positive patients treated with ART (The duration of ART was between 2 and 148 months).

Exclusion criteria were: patients receiving treatment for another illness (chronic kidney disease, chronic steroid, and appetite suppressant therapy) and participants with incomplete evaluation or data (4\%) relevant to this study.

The HIV populations were recruited consecutively at the HIV clinic. HIV-negative subjects were recruited from patients' relatives, community members, and hospital staff. The three groups in this study were age and sex matched.

The ethical committee of the Federal Medical Center, Ido Ekiti approved the study. Individuals gave informed consent to participate in the study. All data were anonymized in the analysis.

\section{Data collection}

Eligible participants were evaluated using a structured questionnaire, physical examination, and blood and urine tests. The questionnaire included demographic information such as sex, level of education, employment status, and monthly income. Clinical information included medical history (with special emphasis on HIV-specific history, drug use history, and history of hypertension). The standardized interview instruments, physical examinations, and laboratory assays were identical in the three groups. These were performed by the same set of trained research personnel and completed in the same laboratories.

In the physical examination, height, weight, and blood pressure (BP) were measured according to the World Health Organization STEP protocol. ${ }^{25}$ Body mass index (BMI) was calculated as weight $(\mathrm{kg})$ divided by the square of height $\left(\mathrm{m}^{2}\right)$ and categorized using the standardized definition of the World Health Organization: ${ }^{26}$ a BMI $<18.5 \mathrm{~kg} / \mathrm{m}^{2}$ as underweight; $18.5-24.9 \mathrm{~kg} / \mathrm{m}^{2}$ as normal weight; $25.0-29.9 \mathrm{~kg} / \mathrm{m}^{2}$ as overweight; and $\geq 30 \mathrm{~kg} / \mathrm{m}^{2}$ as obese. Hypertension was defined as a clinical diagnosis with $\mathrm{BP} \geq 140 / 90 \mathrm{mmHg}$ on two separate occasions after the initial screening. ${ }^{27}$ Blood samples were drawn to determine HIV status and cluster of differentiation (CD)4 T-cell count. HIV status was assessed by HIV-1/ HIV-2 enzyme-linked immunosorbent assay (Genscreen ultra HIV Ag-Ab; Bio-Rad Laboratories, Hercules, CA, USA) of EDTA (ethylenediaminetetraacetic acid) anticoagulated blood samples at the National Blood Transfusion Service laboratory (owned by the Federal Government of Nigeria to provide safe blood). Positive samples were confirmed using Western blot-I and -II confirmation kit (New LAV-BLOT I and II; Bio-Rad Laboratories).

In this study, drug-naïve subjects were defined as those who did not report any current or previous use of antiretroviral 
drugs. Subjects who were ART-experienced were defined as those who reported current and or previous use of antiretroviral drugs. The comparison cohorts were chosen with the assumption that the impact of HIV and/or ART on hypertension and obesity, respectively, endures after infection or use. HAART was defined as: two or more nucleoside reverse transcriptase inhibitors (NRTIs) in combination with at least one protease inhibitor (PI) or one nonnucleoside reverse transcriptase inhibitor (NNRTI); one NRTI in combination with at least one PI and at least one nonnucleoside NRTI; or tenofovir-containing regimen of three or more NRTIs. In this study, all patients on ART received HAART. ART in this paper was used interchangeably with HAART.

\section{Data analyses}

The data were analyzed using Statistical Packaging for Social Sciences version 16 (IBM Corporation, Armonk, NY, USA). Continuous variables were expressed as mean \pm standard deviation, and categorical variables as percentages. The Student's $t$-test was used to determine the statistical significance of the continuous variables, while the chi-square or Fisher's exact test were used to determine the statistical significance of categorical variables. Means of the three groups were compared using one-way analysis of variance. Multiple comparisons of the groups were performed using the post hoc Bonferroni test, with 95\% confidence interval. A multivariate linear regression model was applied to test the independent role of different confounders. In these tests, a $P$-value $<0.05$ was considered statistically significant.

\section{Results}

This study included 403 participants who met the inclusion criteria. Group 1 consisted of 153 (38.0\%) subjects who were HIV negative. There were 65 (42.5\%) male subjects and 88 (57.5\%) female subjects, with a mean age of $35.5 \pm 7.6$ years (range: 17-53 years). Group 2 consisted of 120 (29.8\%) subjects who were HIV positive and drug-naïve. There were $51(42.5 \%)$ male subjects and 69 (57.5\%) female subjects, with a mean age of 36.5 \pm 9.1 years (range: 13-52 years). Group 3 consisted of 130 (32.2\%) subjects who were HIV positive and treated with ART. There were 43 (33.1\%) male subjects and $87(66.9 \%)$ female subjects, with a mean age of 38.6 \pm 8.0 years (range: $19-52$ years). There were no differences in age and sex ( $P=0.648$ and 0.119 , respectively) between the groups, as shown in Table 1 . Most (98\%) of the HIV patients on ART were receiving zidovudine, lamivudine, and nevirapine, while the remaining $2 \%$ were receiving tenofovir, lamivudine, and boosted lopinavir (lopinavir coformulated with low-dose ritonavir). The duration of ART was between 2 and 148 months (mean, 34.1 29.6 months).

Table 1 shows that the prevalence of hypertension among the three groups was not significantly different $(P=0.712)$ and there were no differences between any two groups. There were no significant differences among the groups in mean systolic BP $(P=0.232)$ or mean diastolic BP $(P=0.373)$, nor between any two groups. There was a statistically significant difference in the prevalence of obesity among the three groups $(P<0.001)$, with a significant difference between HIV-negative and HIV-positive drug-naïve subjects $(P<0.001)$, and HIV-negative and HIV-positive ART

Table I Demographic parameters, anthropometric measurements, body mass index, blood pressure, CD4 cell count, HIV, and antiretroviral treatment status

\begin{tabular}{|c|c|c|c|c|}
\hline Variables & HIV-negative & HIV-positive drug-naïve & HIV-positive on ART & $P$-value \\
\hline Age (years) ${ }^{a}$ (range) & $35.5 \pm 7.6(17-53)$ & $36.5 \pm 9.1(13-52)$ & $38.6 \pm 8.0(19-52)$ & 0.648 \\
\hline \multicolumn{5}{|l|}{ Sex } \\
\hline Male & $65(42.48 \%)$ & $5 \mathrm{I}(42.50 \%)$ & $43(33.08 \%)$ & 0.119 \\
\hline Female & $88(57.52 \%)$ & $69(57.50 \%)$ & 87 (66.92\%) & \\
\hline Total & $153(100.00 \%)$ & $120(100.00 \%)$ & $130(100.00 \%)$ & \\
\hline Hypertension ${ }^{\mathrm{b}}$ & 21 (13.73\%) & $19(19.00 \%)$ & $16(12.31 \%)$ & 0.712 \\
\hline \multicolumn{5}{|l|}{ Blood pressure $(\mathrm{mmHg})^{\mathrm{a}}$} \\
\hline sBP (range) & $118.3 \pm 14.1(100-176)$ & $122.6 \pm 16.5(100-170)$ & $118.6 \pm 14.3(90-170)$ & 0.232 \\
\hline dBP (range) & $75.7 \pm 9.2(60-100)$ & $74.6 \pm 15.2(40-100)$ & $73.5 \pm 10.3(60-100)$ & 0.373 \\
\hline Obesity & $23(15.90 \%)$ & $3(3.00 \%)$ & $8(8.00 \%)$ & $<0.001$ \\
\hline BMI $\left(\mathrm{kg} / \mathrm{m}^{2}\right)^{\mathrm{a}}$ (range) & $25.5 \pm 4.6(17-37)$ & $22.6 \pm 4.7(15-37)$ & $23.1 \pm 4.3(14-42)$ & $<0.001$ \\
\hline Overweight $\left(\mathrm{kg} / \mathrm{m}^{2}\right)^{\mathrm{a}}$ (range) & $27.1 \pm 1.4(25-29)$ & $26.8 \pm 1.6(25-29)$ & $26.4 \pm 1.3(25-29)$ & 0.201 \\
\hline Weight (kg)a (range) & $69.3 \pm 13.2(41-102)$ & $61.7 \pm 15.2(38-114)$ & $63.0 \pm 12.5(40-103)$ & 0.001 \\
\hline CD4 cell count (cells $\left./ \mathrm{mm}^{3}\right)^{\mathrm{a}}$ (range) & $854.1 \pm 264.0(\mid 44-1,695)$ & $371.8 \pm 210.6(42-928)$ & $376.9 \pm 234.3(38-I, I 50)$ & $<0.001$ \\
\hline
\end{tabular}

Notes: aMean \pm standard deviation; ${ }^{b}$ proportion.

Abbreviations: ART, antiretroviral therapy; BMI, body mass index; $C D$, cluster of differentiation; dBP, diastolic blood pressure; HIV, human immunodeficiency virus; sBP, systolic blood pressure. 
subjects $(P=0.007)$, but not between HIV-positive drugnaïve subjects and HIV-positive ART subjects $(P=0.227)$. There was also a significant difference among the three groups in BMI $(P<0.001)$. Group comparisons showed a significant difference in BMI between HIV-negative and HIV-positive drug-naïve subjects $(P=0.001)$, and between HIV-negative and HIV-positive ART subjects $(P=0.002)$, but not between HIV-positive drug-naïve and HIV-positive ART subjects $(P=1.000)$. There were also similar significant differences in CD4 count among the groups $(P<0.001)$, with significant differences between the HIV-negative and HIV-positive drug-naïve subjects $(P<0.001)$, and between the HIV-negative and HIV-positive ART subjects $(P<0.001)$, but not between HIV-positive drug-naïve and HIV-positive ART subjects $(P=1.000)$.

Figure 1 shows two distinct age patterns of hypertension distribution. In HIV-negative and HIV-positive ART subjects, the proportion of subjects with hypertension rose rapidly from a rather low level in early adulthood, reached a peak at 40-49 years, and then decreased. A similar trend was observed in HIV-positive drug-naïve subjects, but with an earlier peak at 30-39 years. In Figure 2, both overweight and obesity were shown to have a similar distribution with a rapid rise to a peak at 40-49 years and then a decrease in both HIV-negative and HIV-positive ART subjects. The HIV-positive drug-naïve group showed a rapid rise in overweight, with a peak at 30-39 years followed by a decrease. In this group, only two age categories showed obesity (20-29 and 30-39 years).

In Table 2, binary regression analysis found that sex, CD4 T-lymphocyte cell count, educational attainment, HIV status, ART status, and duration of ART were not significantly associated with hypertension, but hypertension was significantly associated with BMI $(P<0.05)$. In Table 3, BMI was significantly associated with hypertension $(P<0.05)$ when HIV or ART status was included in the model, but not with ART duration. The relationship between CD4 T-lymphocyte cell count and BMI was significant when HIV status was included in the model, but not when ART status or ART duration was included. The odds of being hypertensive increases as BMI increases (odds ratio: 4.531 and 6.434, respectively; 95\% confidence interval: 1.513-13.571 and 1.158-35.767, respectively). Obesity was independently associated with hypertension $(P<0.05)$ except when ART duration was included in the model. In addition, obesity was independently associated with HIV status $(P=0.030)$. HIV-negative patients were significantly more likely to be obese than HIV-positive

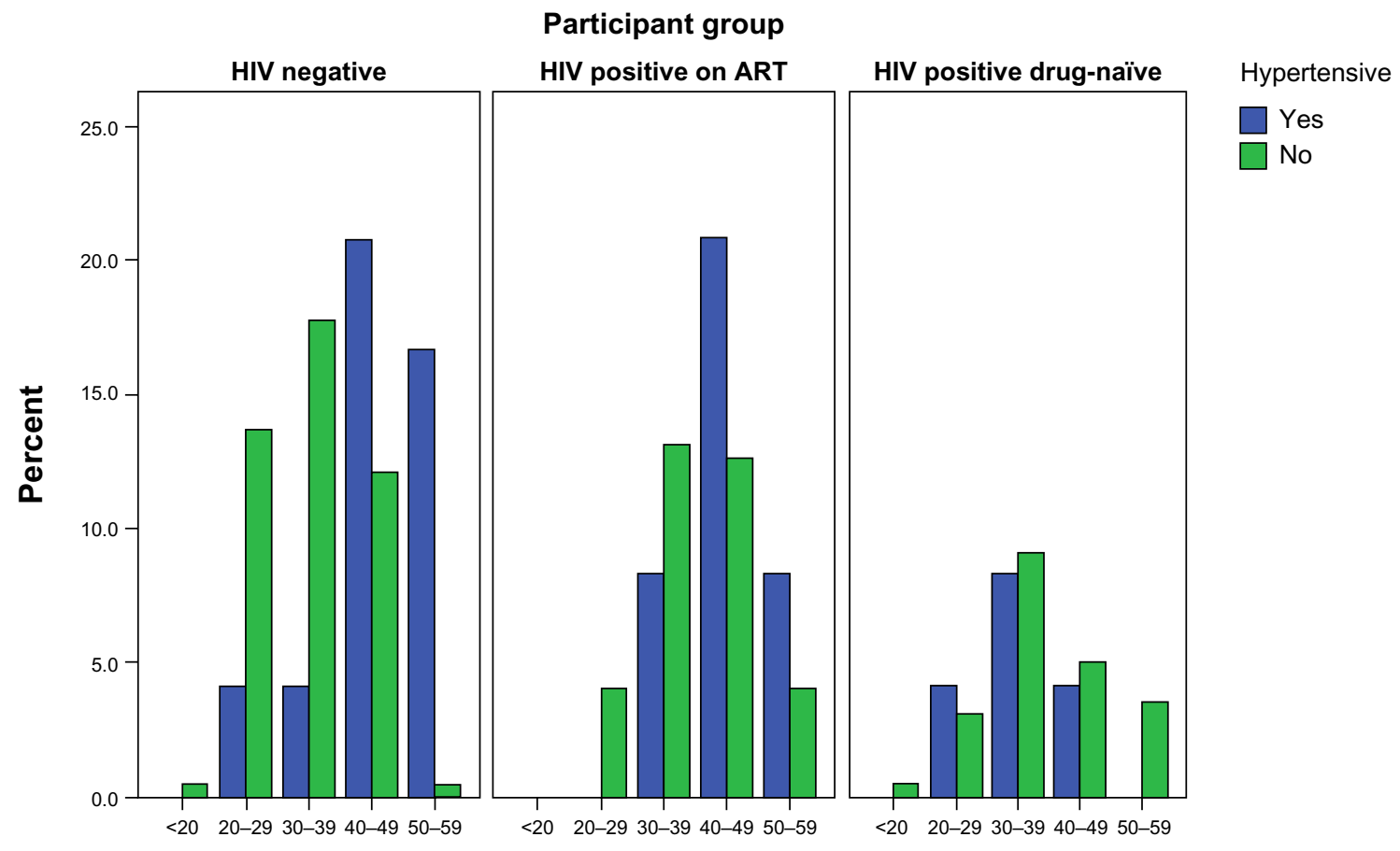

Age group (years)

Figure I Prevalence of hypertension by age group according to HIV and antiretroviral status. Abbreviations: ART, antiretroviral treatment; HIV, human immunodeficiency virus. 


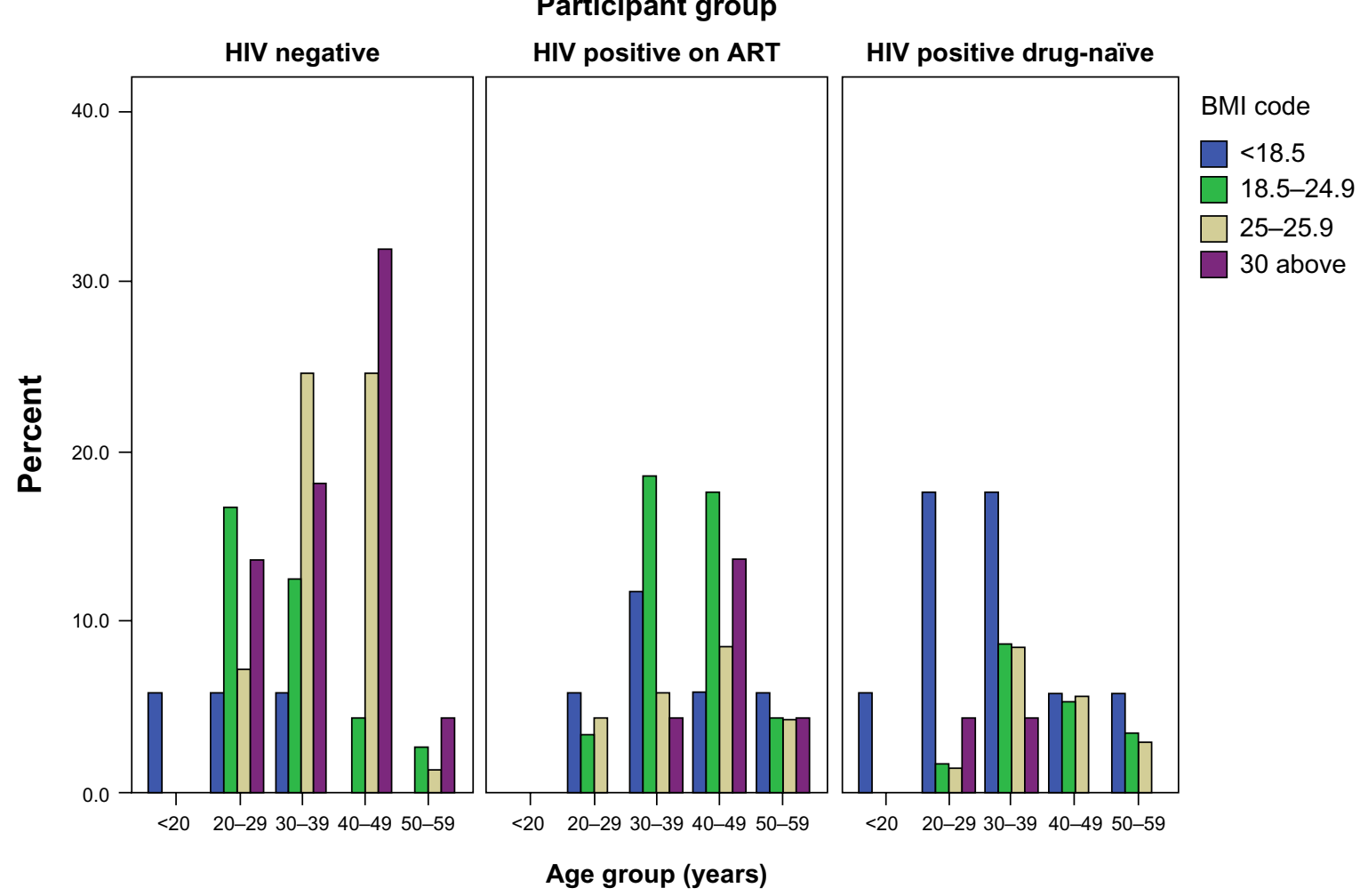

Figure 2 Distribution of body mass index by age group according to HIV and antiretroviral status.

Abbreviations: ART, antiretroviral treatment; BMI, body mass index; HIV, human immunodeficiency virus.

Table 2 Binary logistic regression model for hypertension including confounders

\begin{tabular}{|c|c|c|c|c|c|c|c|c|}
\hline \multirow[t]{2}{*}{ Variable } & \multirow[t]{2}{*}{ B } & \multirow[t]{2}{*}{ SE } & \multirow{2}{*}{$\begin{array}{l}\text { Wald } \\
\text { statistic }\end{array}$} & \multirow[t]{2}{*}{$d f$} & \multirow[t]{2}{*}{$P$-value } & \multirow{2}{*}{$\frac{\text { Odds ratios }}{\operatorname{EXP}(B)}$} & \multicolumn{2}{|c|}{$95 \% \mathrm{Cl}$ of OR } \\
\hline & & & & & & & Lower & Upper \\
\hline \multicolumn{9}{|c|}{ Hypertensive or normotensive (dependent variable) versus HIV status } \\
\hline Sex & 0.115 & 0.529 & 0.047 & I & 0.827 & 1.122 & 0.398 & 3.166 \\
\hline CD4 cell count (cells $\left./ \mathrm{mm}^{3}\right)$ & 0.000 & 0.001 & 0.674 & I & 0.412 & 0.999 & 0.997 & 1.001 \\
\hline Educational attainment & -0.001 & 0.324 & 0.000 & I & 0.997 & 0.999 & 0.530 & 1.883 \\
\hline BMI $\left(\mathrm{kg} / \mathrm{m}^{2}\right)$ & -0.146 & 0.048 & 9.174 & 1 & 0.002 & 0.864 & 0.786 & 0.950 \\
\hline HIV status & -0.707 & 0.672 & 1.108 & I & 0.293 & 0.493 & 0.132 & 1.840 \\
\hline Constant $^{\prime}$ & 6.633 & 1.825 & 13.208 & I & $<0.001$ & 760.000 & & \\
\hline \multicolumn{9}{|c|}{ Hypertensive or normotensive (dependent variable) versus ART status } \\
\hline Sex & 0.039 & 0.752 & 0.003 & I & 0.959 & 1.040 & 0.238 & 4.538 \\
\hline CD4 cell count (cells $/ \mathrm{mm}^{3}$ ) & 0.000 & 0.001 & 0.129 & I & 0.719 & 1.000 & 0.997 & 1.002 \\
\hline Educational attainment & 0.009 & 0.397 & 0.000 & I & 0.983 & 1.009 & 0.463 & 2.197 \\
\hline BMI $\left(\mathrm{kg} / \mathrm{m}^{2}\right)$ & -0.232 & 0.074 & 9.945 & I & 0.002 & 0.793 & 0.686 & 0.916 \\
\hline ART status & 0.383 & 0.705 & 0.295 & I & 0.587 & 1.466 & 0.368 & 5.836 \\
\hline Constant $^{\prime}$ & 7.861 & 2.044 & 14.784 & I & $<0.001$ & $2.593 \mathrm{E} 3$ & & \\
\hline \multicolumn{9}{|c|}{ Hypertensive or normotensive (dependent variable) versus ART duration } \\
\hline Sex & 0.293 & 0.986 & 0.088 & I & 0.767 & 1.340 & 0.194 & 9.257 \\
\hline CD4 cell count (cells $\left./ \mathrm{mm}^{3}\right)$ & 0.002 & 0.002 & 0.684 & I & 0.408 & 1.002 & 0.998 & 1.006 \\
\hline Educational attainment & -0.098 & 0.523 & 0.035 & I & 0.852 & 0.907 & 0.325 & 2.527 \\
\hline BMI $\left(\mathrm{kg} / \mathrm{m}^{2}\right)$ & -0.279 & 0.101 & 7.550 & I & 0.006 & 0.757 & 0.620 & 0.923 \\
\hline Duration on ART & -0.016 & 0.013 & 1.515 & I & 0.218 & 0.984 & 0.959 & 1.010 \\
\hline Constant $^{\prime}$ & 9.107 & 2.963 & 9.449 & I & 0.002 & $9.020 \mathrm{E} 3$ & & \\
\hline
\end{tabular}

Abbreviations: ART, antiretroviral treatment; $B$, regression coefficient; BMI, body mass index; CD, cluster of differentiation; Cl, confidence interval; Constant', baseline

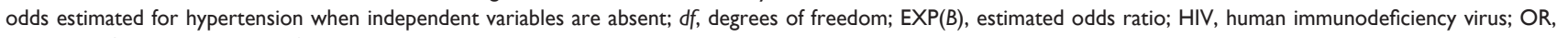
odds ratio; SE, standard error of the estimate. 
Table 3 Binary logistic regression model for obesity including confounders

\begin{tabular}{|c|c|c|c|c|c|c|c|c|}
\hline \multirow[t]{2}{*}{ Variable } & \multirow[t]{2}{*}{ B } & \multirow[t]{2}{*}{ SE } & \multirow[t]{2}{*}{ Wald } & \multirow[t]{2}{*}{$d f$} & \multirow[t]{2}{*}{$P$-value } & \multirow{2}{*}{$\frac{\text { Odds ratios }}{\operatorname{EXP}(B)}$} & \multicolumn{2}{|c|}{$95 \% \mathrm{Cl}$ of OR } \\
\hline & & & & & & & Lower & Upper \\
\hline \multicolumn{9}{|c|}{ Obese or nonobese (dependent variable) versus HIV status } \\
\hline Sex & $0.41 \mathrm{I}$ & 0.580 & 0.502 & I & 0.478 & 1.509 & 0.484 & 4.705 \\
\hline CD4 cell count (cells $\left./ \mathrm{mm}^{3}\right)$ & -0.002 & 0.001 & 5.296 & I & 0.021 & 0.998 & 0.996 & 1.000 \\
\hline Educational attainment & -0.211 & 0.389 & 0.294 & I & 0.588 & 0.810 & 0.378 & 1.736 \\
\hline Hypertensive & $1.51 \mathrm{I}$ & 0.560 & 7.287 & I & 0.007 & 4.531 & 1.513 & |3.57| \\
\hline HIV status & -1.270 & 0.585 & 4.709 & I & 0.030 & 0.281 & 0.089 & 0.884 \\
\hline Constant $^{1}$ & 1.577 & 2.091 & 0.569 & I & 0.451 & 4.839 & & \\
\hline \multicolumn{9}{|c|}{ Obese or nonobese (dependent variable) versus ART status } \\
\hline Sex & 0.987 & 1.165 & 0.718 & I & 0.397 & 2.684 & 0.273 & 26.346 \\
\hline CD4 cell count (cells $\left./ \mathrm{mm}^{3}\right)$ & -0.002 & 0.001 & 2.746 & I & 0.098 & 0.998 & 0.995 & 1.000 \\
\hline Educational attainment & -0.586 & 0.552 & 1.127 & I & 0.288 & 0.557 & 0.189 & 1.642 \\
\hline Hypertensive & 1.862 & 0.875 & 4.525 & I & 0.033 & 6.434 & 1.158 & 35.767 \\
\hline ART status & 0.490 & 0.918 & 0.285 & I & 0.593 & 1.633 & 0.270 & 9.873 \\
\hline Constant $^{1}$ & 2.125 & 2.582 & 0.677 & I & 0.411 & 8.371 & & \\
\hline \multicolumn{9}{|c|}{ Obese or nonobese (dependent variable) versus duration on ART } \\
\hline Sex & 0.182 & 1.230 & 0.022 & I & 0.882 & 1.200 & 0.108 & 13.382 \\
\hline CD4 cell count (cells $\left./ \mathrm{mm}^{3}\right)$ & -0.003 & 0.002 & 2.629 & I & 0.105 & 0.997 & 0.994 & 1.001 \\
\hline Educational attainment & -0.226 & 0.620 & 0.132 & I & 0.716 & 0.798 & 0.237 & 2.692 \\
\hline Hypertensive & 2.081 & 1.091 & 3.636 & I & 0.057 & 8.012 & 0.944 & 68.013 \\
\hline Duration on ART & 0.015 & 0.018 & 0.697 & I & 0.404 & 1.015 & 0.980 & 1.052 \\
\hline Constant ${ }^{1}$ & 0.360 & 2.877 & 0.016 & I & 0.901 & 1.433 & & \\
\hline
\end{tabular}

Abbreviations: ART, antiretroviral treatment; $B$, regression coefficient; BMI, body mass index; $C D$, cluster of differentiation; Cl, confidence interval; Constant', baseline odds estimated for hypertension when independent variables are absent; $d f$, degree of freedom; HIV, human immunodeficiency virus; OR, odds ratio; SE, standard error of the estimate.

patients (odds ratio: $0.281 ; 95 \%$ confidence interval: 0.089-0.884).

\section{Discussion}

This study found a lack of a significant association between hypertension and HIV infection or ART status in the univariate analysis, even after adjustment for other factors associated with hypertension. The proportion of hypertensive individuals observed among HIV-negative and HIV-positive drug-naïve subjects was similar to the general prevalence in our region as reported by Cooper et $\mathrm{al}^{8}$ and Akinkugbe. ${ }^{28}$ The prevalence in HIV-positive ART subjects (9\%) was lower than that reported by Cooper et $\mathrm{al}^{8}$ and Akinkugbe ${ }^{28}(14.5 \%$ and $20 \%-25 \%$, respectively) in the general population. However, there was no statistically significant difference between groups in our study. Therefore, our data do not support a concern that HIV infection or ART are risk factors for hypertension. In developed countries, the prevalence of hypertension in HIV-positive individuals varies between $8 \%$ and $39 \% .{ }^{29,30}$ This is similar to the finding in our study. In Africa, a study in Kenya reported a lower prevalence of $7.4 \%-11.2 \%,{ }^{31}$ compared with $12.3 \%-$ $19.0 \%$ in the current study. This may be related to a lower prevalence of hypertension in Kenya $(12.3 \%)^{32}$ compared with Nigeria $\left(14.5 \%{ }^{23}\right.$ and $\left.20 \%-25 \%{ }^{28}\right)$. There was a similarity in the distribution of hypertension by age group according to HIV and ART status in our study. This, coupled with the lack of a significant difference between the groups, suggests that HIV and ART status do not add to the risk factors for hypertension in the general population. We did not observe any significant association between CD4 T-cell count and hypertension, unlike that which Manner et $\mathrm{al}^{33}$ recently reported. The difference in observation might have resulted from difference in methodology. In our study, we determined the CD4 T-cell count at the time of BP measurement; Manner et al did not determine hypertension status at the time of CD4 cell count determination in their longitudinal design, and the classification of hypertension status according to the average of several BP measurements with variable time intervals was not optimal. Therefore, association between CD4 T-cell and blood pressure in HIV patients requires further exploration.

There was a high prevalence of obesity in the HIV-negative group. This was similar to previous reports in Nigeria ${ }^{5,6}$ and in other parts of the world. ${ }^{7,34}$ There are a number of possible reasons. First, there has been an epidemiological transition from diseases of poverty to those of affluence and a Westernized lifestyle. Second, there are local sociobehavioral factors in which being overweight or obese is perceived by the community as a sign of wealth, and is therefore attractive, 
and is associated with respect, dignity, and popularity. ${ }^{35}$ Third, in an area of high HIV prevalence like Nigeria, leanness is often associated with suspicion of HIV. This, therefore, often discourages an average person from maintaining an acceptable weight or embarking on a weight reduction program. ${ }^{35}$ Fourth, it has also been observed that in low- and middle-income countries, the burden of obesity has shifted to rural areas (Nigeria being predominantly rural), and that the highest prevalence of obesity is in middle-age groups. ${ }^{36}$ Fifth, sedentary work is now one of the most common occupations in Nigeria. ${ }^{6}$ Sedentary behavior is known to be associated with obesity, independent of leisure-time physical exercise. ${ }^{37,38}$ Sixth, in the rural community in Nigeria, people go to bed early at night because of a lack of social amenities. This practice tends to increase their sleep duration, which has been associated with obesity. ${ }^{39}$

There was no significant difference in the prevalence of obesity and mean BMI between HIV-positive drug-naïve and HIV-positive ART subjects. Similarly, there was no significant difference between these two groups in mean CD4 T-cell count. The analysis indicated that there was no significant relationship between obesity and ART status, but there was an association between obesity and HIV status. Our study observed significant association between BMI and CD4 T-cell count when HIV status was considered in a binary multivariate regression model. However, the impact of weight on immune cell levels among HIV-infected persons during the ART era remains largely unknown. A study noted that obese HIV patients had similar CD4 cell counts as compared to normal-weight persons. ${ }^{40}$ Nevertheless, this study was limited by its population consisting only of diabetic patients and lack of data on HIV duration. In agreement with our study, Crum-Cianflone et $\mathrm{al}^{41}$ reported that weight appears to affect immune cell counts over the course of infection. We also found that BMI was a stronger predictor of hypertension in our analysis, even after adjustment for other factors associated with BMI. The lower prevalence of obesity in HIV-positive subjects may reflect HIV-related wasting syndrome. It is also possible that HIV-infected patients are more in contact with health care services, so they may be more likely to obtain nutrition-related advice. Findings from developed countries suggest that PI use may be a factor in both obesity and hypertension. ${ }^{42}$ It was unlikely that PI use had any significant influence on hypertension and obesity in our sample because the proportion of people using PIs was low $(2.0 \%)$. In addition, regression analysis failed to show a precise relationship between length of time taking ART or type of ART and obesity or hypertension. Our study was in agreement with a similar study in South Africa ${ }^{43}$ showing a higher prevalence of obesity in HIV-negative subjects; but, in contrast to our study, HIV-positive ART subjects were reported to have a significantly lower prevalence of obesity and lower BMI than HIV drug-naïve subjects. The reason for this difference may be because of the difference in methodology. Our study recruited HIV-positive patients referred to an HIV clinic whereas the South African study was a population-based survey in which participants were recruited within a surveillance area where the diagnostic test was conducted and, therefore, the participants may have been recruited at an earlier stage.

The population recruited for this study consisted of about $80 \%$ young adults and $61.1 \%$ female subjects. This is consistent with epidemiological evidence in Nigeria and other parts of Africa that showed that HIV infection is more common in young adults and in female individuals.,44 In Tanzania, the prevalence in both women and men increases with age until it reaches a peak: for women at age 30-34 years and for men at age 40-44 years. ${ }^{44}$ This unimodal distribution (of HIV infection and therefore age-matched HIV-negative groups) might have been responsible for reduction in the proportion of hypertensive subjects seen after 30-39 years of age, especially considering the fact that only about $20 \%$ were middle-aged. The commonality of female sex in HIV infection and overweight/obesity ${ }^{4,44,45}$ may further explain the distribution because $61.1 \%$ of our studied population was female. The early peak in overweight and fewer obese subjects in the HIV-positive drug-naïve group may be due to late presentation and the possible influence of HIV-related wasting syndrome.

Our study has some limitations. First, analysis of cardiovascular risk factors was limited to hypertension and obesity. Other conventional cardiovascular risk factors such as tobacco use, blood lipids, diabetes mellitus, physical activity, alcohol consumption, and dietary factors were not included in our analysis. However, hypertension or obesity are independent cardiovascular risk factors. Second, only patients who reported to our clinic were included in this study, therefore, selection bias might have been introduced. Third, those with illnesses other than our main predictor of interest and outcome measures were excluded. This may therefore limit the generalizability of our study. Fourth, nonrandom or community-based selection of HIV-uninfected controls might have also introduced selection bias. Fifth, much of the discussion in our study was based on factors that are associated with obesity in the general population, even though this was not a population-based study. Sixth, the low proportion of patients 
( $2 \%)$ who were exposed to PIs limits the study's relevance regarding long-term exposure to these drugs.

In conclusion, HIV or ART status in our study did not appear to add any extra burden of hypertension prevalence compared with HIV-negative subjects. The prevalence of hypertension in each group was found to be similar to that reported in the general population. Consistent with current knowledge, hypertension was strongly associated with BMI. This study also confirmed that HIV infection was associated with a lower BMI and, thus, a lower prevalence of obesity compared with HIV-negative subjects. As excess weight was associated with hypertension, and obesity was present in a proportion of HIV-infected patients, there is good reason to support cardiovascular risk assessment as part of routine HIV clinical care.

\section{Acknowledgments}

We thank the study participants for their contributions to this research, and members of staff of the HIV Clinic and Hematology Department of Federal Medical Center, Ido Ekiti, Ekiti State, Nigeria for their invaluable support. The Western blot and enzyme-linked immunosorbent assay (ELISA) kits were sponsored by the authors. This did not in any way modify our judgment in this work.

\section{Disclosure}

The authors report no conflicts of interest in this work.

\section{References}

1. Global Health Observatory. HIV/AIDS global situation trends [webpage on the Internet]. Geneva: World Health Organization. Available from: http://www.who.int/gho/hiv/en/. Accessed June 28, 2013.

2. HIV/AIDS Statistics and Surveillance. [webpage on the Internet]. Atlanta: Centers for Disease Control and Prevention; 2011. Available from: http:// www.cdc.gov/hiv/topics/surveillance/basic.htm\#incidence. Accessed June 28, 2013.

3. Joint United Nations Programme on HIV/AIDS (UNAIDS). Global Report: UNAIDS Report on the Global AIDS Epidemic 2013. Geneva, Switzerland: UNAIDS; 2013. Available from: http://www.unaids.org/ en/media/unaids/contentassets/documents/epidemiology/2013/gr2013/ UNAIDS_Global_Report_2013_en.pdf. Accessed February 3, 2014.

4. National Agency for the Control of AIDS (NACA). United Nations General Assembly Special Session (UNGASS) Country Progress Report: Nigeria. Reporting period: Jan 2008-Dec 2009. Abuja, Nigeria: NACA; 2010. Available from: http://data.unaids.org/Pub/report/2010/ nigeria_2010_country_progress_report_en.pdf. Accessed February 3, 2014.

5. Chukwuonye II, Chuku A, John C, et al. Prevalence of overweight and obesity in adult Nigerians - a systematic review. Diabetes Metab Syndr Obes. 2013;6:43-47.

6. Ogunmola OJ, Olaifa AO, Oladapo OO, Babatunde OA. Prevalence of cardiovascular risk factors among adults without obvious cardiovascular disease in a rural community in Ekiti State, Southwest Nigeria. BMC Cardiovasc Disord. 2013;13:89.

7. Prentise AM. The emerging epidemic of obesity in developing countries. Int J Epidemiol. 2006;35:93-99.
8. Cooper R, Rotimi C, Ataman S, et al. The prevalence of hypertension in seven populations of west Africa origin. Am J Public Health. 1997;87:160-168.

9. Wolf-Maier K, Cooper RS, Banegas JR, et al. Hypertension prevalence and blood pressure level in six European countries, Canada, and the United States. JAMA. 2003;289:2363-2369.

10. McDonald CL, Kaltman JR. Cardiovascular disease in adult and pediatric HIV/AIDS. J Am Coll Cardiol. 2009;54:1185-1188.

11. Ntsekhe M, Hakim J. Impact of human immunodeficiency virus infection on cardiovascular disease in Africa. Circulation. 2005;112: 3602-3607.

12. Grunfeld C, Delaney JA, Wanke C, et al. Preclinical atherosclerosis due to HIV infection: carotid intima-media thickness measurements from the FRAM study. AIDS. 2009;23:1841-1849.

13. Randell P, Moyle G. Antiretroviral therapy with heart. Am J Ther. 2009;16:579-584.

14. Federal Ministry of Health Nigeria. National Guidelines for HIV and AIDS Treatment and Care in Adolescents and Adults. Abuja: Federal Ministry of Health Nigeria; 2010. Available from: http://www.who.int/ hiv/amds/Nigeria_adult_2007.pdf. Accessed June 18, 2013.

15. Palella FJ Jr, Delaney KM, Moorman AC, et al. Declining morbidity and mortality among patients with advanced human immunodeficiency virus infection. HIV Outpatient Study Investigators. $N$ Engl J Med. 1998;338:853-860.

16. Giannarelli C, Klein RS, Badimon JJ. Cardiovascular implications of HIV-induced dyslipidaemia. Atheroscelerosis. 2010;219:384-389.

17. D:A:D Study Group, Sabin CA, Worm SW, et al. Use of nucleoside reverse transcriptase inhibitors and risk of myocardial infarction in HIV infected patients enrolled in the DAD study: a multi-cohort collaboration. Lancet. 2008;371:1417-1426.

18. DAD Study Group, Friis-Møller N, Reiss P, et al. Class of antiretroviral drugs and the risk of myocardial infarction. $N$ Eng $J$ Med. 2007;356:1723-1735.

19. Joubert J, Bradshaw D. Population ageing and health challenges in South Africa. In: Steyn K, Fourie J, Temple N, editors. Chronic Diseases of Lifestyle in South Africa 1995-2005. Cape Town: South Africa Medical Research Council. http://www.mrc.ac.za/chronic/cd11995-2005.pdf. February 3, 2014.

20. Ekere $\mathrm{Au}$, yellowe $\mathrm{Be}$, Umune $\mathrm{S}$. Mortality patterns in the accident and emergency department of an urban hospital in Nigeria. Nigeria J Clin Pract. 2005;8:14-18.

21. Ogunniyi A, Baiyewu O, Gureje O, et al. Morbidity pattern in a sample of elderly Nigerians resident in Idikan community, Ibadan. West Afr $J$ Med. 2001;20:227-231.

22. Dubé MP, Lipshultz SE, Fichenbaum CJ, et al. Effects of HIV infection and antiretroviral therapy on the heart and vasculature. Circulation. 2008; 118:e36-e40.

23. Ogunmola JO, Oladosu YO, Olamoyegun MA, et al. Mortality pattern in adult accident and emergency department of a tertiary health centre situated in rural area of developing country. IOSR J Dent Med Sci. 2013;5:12-15.

24. Ogunmola JO, Oladosu YT. Pattern of medical causes of deaths in adult accident and emergency department of a tertiary health centre situated in a rural setting of a developing country. J Med Med Sci. 2013;4: 112-116.

25. World Health Organization. STEPS: A Framework for Surveillance: The WHO STEPwise Approach to Surveillance of Non-communicable Disease (STEPS). Geneva: World Health Organization; 2003.

26. World Health Organization. OBESITY: Preventing and Managing the Global Epidemic. Report of a WHO Consultation on Obesity. Geneva: World Health Organization; 2010.

27. The Seventh Report of the Joint National Committee on Prevention, Detection, Evaluation, and Treatment of High Blood Pressure (JNC 7). JAMA. 2003;289:2560-2572.

28. Akinkugbe OO. Non-communicable Diseases in Nigeria-Final Report of a National Survey. Lagos: Federal Ministry of Health-National Expert Committee on Communicable Disease; 1997:1-12. 
29. Jericó C, Knobel H, Montero M, et al. Hypertension in HIV- infected patients and related factors. Am J Hypertens. 2005;18:1396-1401.

30. Barbaro G. Metabolic and cardiovascular complications of highly active retroviral therapy for HIV infection. Curr HIV Res. 2006;4:79-85.

31. Bloomfield GS, Hogan JW, Keter A, et al. Hypertension and obesity as cardiovascular risk factors among HIV seropositive patients in Western Kenya. PLoS One. 2011;6:e22288.

32. van de Vijver SJ, Oti SO, Agyemang C, Gomez GB, Kyobutungi C. Prevalence, awareness, treatment and control of hypertension among slum dwellers in Nairobi, Kenya. J Hypertens. 2013;31:1018-1024.

33. Manner IW, Trøseid M, Oektedalen O, Baekken M, Os I. Low nadir CD4 cell count predicts sustained hypertension in HIV-infected individuals. J Clin Hypertens (Greenwich). 2013;15(2):101-106.

34. Flegal KM, Carrol MD, Ogden CL, Johnson CL. Prevalence and trend in obesity among US adults, 1999-2000. JAMA. 2002;288:1723-1727.

35. Kruger HS, Puoane T, Senekal M, van der Merwe MT. Obesity in South Africa: challenges for government and health professionals. Public Health Nutr. 2007;8:491-500.

36. Swinburnn BA, Sacks G, Hall KD, et al. The global obesity pandemic: shaped by global drivers and local environments. Lancet. 2011;378: 804-814.

37. Shields M, Tremblary MS. Sedentary behavior and obesity. Health Rep. 2008;19:19-30.

38. Hu FB, Li TY, Colditz GA, Willett WC, Manson JE. Television watching, and other sedentary behavior in relation to risk of obesity and type 2 diabetes mellitus in women. JAMA. 2003;289:1785-1791.
39. Bo S, Ciccone G, Durazzo M, et al. Contributors to the obesity and hyperglycemia epidemics. A prospective study in a population-based cohort. Int J Obes (Lond). 2011;35:1442-1449.

40. Adeyemi OM, Vibhakar S, Evans AT. Obesity and lymphocyte subsets in virologically suppressed HIV-infected patients. Metabolism. 2009;58:1285-1287.

41. Crum-Cianflone NF, Roediger M, Eberly LE: Impact of Weight on Immune Cell Counts among HIV-Infected Persons. Clin Vaccine Immunol. 2011;18(6):940-946.

42. Kaplan RC, Kingsley LA, Sharrett AR, et al. Ten-year predicted coronary heart disease risk in HIV-infected men or women. Clin Infect Dis. 2007;45:1074-1081.

43. Malaza A, Mossong J, Bärnighausen T, Newell ML. Hypertension and obesity in adults living in a high HIV prevalence rural area in South Africa. PloS One. 2012;7:e47761.

44. National Bureau of Statistics Tanzania. Tanzania HIV/AIDS Indicator Survey 2003-2004. Dar es Salaam: National Bureau of Statistics (NBS), Ministry of Planning, Empowerment and Economics, Data producer; 2010. Available from: http://www.nbs.go.tz/tnada/index.php/catalog/6/ download/23. Accessed 5 March, 2013.

45. Case A, Menendez A. Sex differences in obesity rates in poor countries: evidence from South Africa. Econ Hum Biol. 2009; 7:271-282.
Vascular Health and Risk Management

\section{Publish your work in this journal}

Vascular Health and Risk Management is an international, peerreviewed journal of therapeutics and risk management, focusing on concise rapid reporting of clinical studies on the processes involved in the maintenance of vascular health; the monitoring, prevention and treatment of vascular disease and its sequelae; and the involvement of

\section{Dovepress}

metabolic disorders, particularly diabetes. This journal is indexed on PubMed Central and MedLine. The manuscript management system is completely online and includes a very quick and fair peer-review system, which is all easy to use. Visit http://www.dovepress.com/ testimonials.php to read real quotes from published authors. 